\title{
Lung histomorphological alterations in rats exposed to cigarette smoke and electronic cigarette vapour
}

\author{
EWELINA WAWRYK-GAWDA ${ }^{1}$, PATRYCJA CHYLIŃSKA-WRZOS ${ }^{1}$, MICHAŁ K. ZAROBKIEWICZ ${ }^{2}$, \\ KATARZYNA CHŁAPEK ${ }^{3}$ and BARBARA JODŁOWSKA-JĘDRYCH ${ }^{1}$ \\ ${ }^{1}$ Department of Histology and Embryology with Experimental Cytology Unit, \\ Medical University in Lublin, 20-080 Lublin; ${ }^{2}$ Department of Clinical Immunology, Medical University in Lublin, \\ 20-093 Lublin; ${ }^{3}$ Department of Financial Accounting, Cracow University of Economics, 31-510 Cracow, Poland
}

Received December 6, 2018; Accepted October 21, 2019

DOI: $10.3892 /$ etm.2020.8530

\begin{abstract}
Electronic cigarettes are becoming increasingly common as a form of nicotine usage, known as vaping. Numerous studies have demonstrated that using electronic cigarettes may lead to nicotine dependence and has a potentially harmful impact on health. The present study compared the impact of electronic and conventional cigarettes on lung tissue. The experiment included 30 male Wistar rats. The animals were divided into three groups: Group A was exposed to electronic cigarette liquid vapour; group B to conventional smoke; and group $\mathrm{C}$ constituted the control group without exposition to the nicotine. In both experimental groups numerous alterations were observed, including a collapse of parenchyma, hyperhagia, hyperplasia of type II of pneumocytes, collagen deposition and an increased number of macrophages within thickened alveolar septa. Additionally, an initial elastolysis was observed. The elastic fibers were disrupted, sparse, irregular and thickened, whereas the numbers of $\alpha$-SMA positive myofibroblasts and blood vessels were highest in the group exposed to conventional cigarette smoke. In conclusion, the usage of the electronic cigarettes leads to milder pathological alterations compared with traditional cigarette smoking. Nevertheless, the histopathological damage caused by vaping may lead to the development of alterations in the lung tissue which consequently hinder gas exchange.
\end{abstract}

\section{Introduction}

The harmful effects of cigarette smoking have been known for decades. Chronic active and passive exposition to smoke increases the risk of pulmonary diseases, lung fibrosis,

Correspondence to: Professor Barbara Jodłowska-Jędrych, Department of Histology and Embryology with Experimental Cytology Unit, Medical University in Lublin, 11 Radziwiłłowska Street, 20-080 Lublin, Poland

E-mail: barbarajodlowskajedrych@umlub.pl

Key words: nicotine, vapour, smoke, lung, electronic cigarettes asthma, cancers, cardiovascular and metabolic diseases (1-4). The harmful effects of cigarette smoking are predominantly associated with nicotine, which is the most biologically active component of the smoke (3). The nicotine receptors are dispersed within the whole body, so the effects on human health are complex $(1,5)$. Most of the inhaled nicotine is absorbed into the blood stream by lungs' cells, and therefore its impact on the lungs themselves is significant $(6,7)$. Additionally, the cigarette smoke deposits in the lung tissue causing chronic inflammation $(4,8)$.

The vapour of electronic cigarettes (e-cig) does not undergo the combustion and is free of tar substances. That is why it is believed to constitute a safer form of 'smoking', also in the treatment of the addiction to conventional cigarettes $(3,9)$. Moreover, since the usage of e-cigs is similar to that of conventional cigarettes, the withdrawal from smoking seems easier than when nicotine gums or patches are used (9-12). E-cig liquids contain different substances which after heating form aerosol (vapour), imitating smoke (13). Except from nicotine, one can find there humectants (propylene glycol, glycerine), concentrated flavours (extracts from herbs or plants) and other mood boosting substances (14). In recent years, some countries have introduced legal regulations referring to the liquid contents e.g. it is forbidden to add both psychoactive substances and sildenafil (15-17). What is more, the regulations additionally limit the access to the electronic cigarettes for adolescents. Nevertheless, these products can be easily purchased on the Internet and are frequently used by minors and young adults (18-20).

The data concerning the safety of e-cig usage are inconsistent. Although it was initially presumed that the e-cig usage was completely safe, subsequent observations proved that vapers alike smokers suffer from numerous disorders and therefore further investigations were conducted $(2,21,22)$. Such problems as pain, dizziness, fever, vomiting, gingivitis, cough, throat irritation as well as severe organizing pneumonia with hypoxemic respiratory failure were reported in e-cig users $(18,10,23,24)$. Vapour may contain additional toxic substances similar to those in conventional cigarettes such as formaldehyde, carbonyls and nitrosamines (8). Those harmful effects may be also caused by trace metals such as nickel, chromium, tin, aluminium, all of which are leached from e-cig core assembly $(25,26)$. 
Yet, the effect of vapour on lung tissue has not been evaluated. Clinical symptoms of lungs function disorders observed in e-cig users may be the consequences of lung tissue histopathological changes. The aim of the current study was to assess the safety of e-cigs in comparison to the conventional cigarettes in an animal model.

\section{Materials and methods}

Experiments. Ourexperiment was conducted on 30 male Wistar rats of average body weight $187,82 \pm 12,56 \mathrm{~g}$ at the beginning of the study. The animals were divided into three groups: A, $\mathrm{B}, \mathrm{C}$. The animals in group A were exposed to scent free e-cig vapour. During the $10 \mathrm{~min}$ exposition, the rats were placed in a $0.1 \mathrm{~m}^{3}$ PCV cage and were exposed to the vapour with the use of the pump $(0.18 \mathrm{~kW} ; 1.4 / 1.6 \mathrm{~A} ; 230 \mathrm{~V} ; 50 / 60 \mathrm{~Hz})$. It was installed on one side of the box, while e-cigarette aerosol was puffed on the other. This mechanism generates airflow into the cage. The cage containing 5 animals at a time was hermetically sealed with the two holes (e-cig and pump connection points) that were left open. Animals were exposed in order to consume $0.6 \mathrm{ml} /$ day of e-liquid containing $12 \mathrm{mg} / \mathrm{ml}$ of nicotine, propylene glycol and water produced by Inawera Dot Com Sp. Z o.o. Sp. K. One cycle of treatment consisted of 5 min puff followed by 20 min stop. During the experiment the e-cig voltage was set at $5.5 \mathrm{~V}$. At the end of the cycle the animals were transferred to a clean cage. Animals were subjected to 1 cycle/day for 5 consecutive days/week, and for 6 consecutive weeks (27) The rats in group B were exposed to the smoke from 10 traditional cigarettes with the same total nicotine dose as in group A. In total, one group of animals was exposed to $210 \mathrm{mg}$ of nicotine. The concentration of nicotine in serum of each rat was not tested. Therefore, it is not possible to precisely define the dose of nicotine received by single rat. Our study is based on the official list of the substances in the liquid as reported by the manufacturer. No additional tests were performed to assess the liquid composition.

The rats in group $\mathrm{C}$ constituted the control group and they were exposed to the same inhalation-related stress that other rats but without the nicotine element. The animals were decapitated without anaesthesia $24 \mathrm{~h}$ after last exposition and their lungs were dissected. Body weight of rats at the time of sacrifice was: 290.73 SD 15,69 g (group A), 287.67 SD $21.34 \mathrm{~g}$ (group B), 324.38 SD 19, 16 g (group C).

Our study involves histological analysis of multiple organs as well as some biochemical and molecular markers measurement by ELISA. Therefore, we had to carefully choose the right euthanasia method, so that it would not affect our results. Due to multiple concerns, we have chosen the decapitation without prior anesthaesia. It was performed by an experienced worker of the Experimental Medicine Facility of the Medical University of Lublin. The $\mathrm{CO}_{2}$ euthanasia is known to negatively affect the lungs, the study of which are important part of our project $(28,29)$. Pentobarbital on the other hand significantly changes the biochemistry of brain, including the acetylcholinesterase activity (30). Moreover, similarly to $\mathrm{CO}_{2}$ it also alters the blood biochemical markers (31). Enflurane, halothane, isoflurane and sevoflurane negatively affect rat sperm (32). Moreover, isoflurane euthanasia significantly impact the metabolism of liver, possibly changing the glycogen levels (33). The cervical dislocation was rejected as it requires prior anesthesia. Concussion on the other hand could significantly damage the brain, therefore, it was also not considered.

To conclude, decaptation was chosen because contrary to other methods accepted by EU Directive 2010/63/EU it does not induce significant changes to any organs except for the neck and does not alter the biochemistry. Bearing the responsibility, we have obtained the necessary approval of Bioethical Committee for the whole experiment, including the decapitation.

After fixing the material in $10 \%$ buffered formalin, the organs were embedded in paraffin blocks. The material was then tailored into $5-\mu \mathrm{m}$-thick sections. The experiment was conducted with the formal approval of the local animal care committees: 'Local Ethics Committee for Animal Experiments' by University of Life Sciences in Lublin (30/2015). The study was carried out in accordance with Directive 2010/63/Eu of The European Parliament and of The Council of 22 September 2010 on The Protection of Animals Used For Scientific Purposes.

Hematoxylin and eosin (H\&E), periodic Acid-Schiff (PAS) and Masson's trichrome staining. The histomorphological evaluation of the tissues stained with $H \& E$ was performed with the use of a light microscope using lenses x10, x40 and $\mathrm{x} 100$. Fifty fields of view from each animal were analysed. Samples were stained by Masson's Trichrome method to assess collagen deposition and fibrosis. PAS staining was done to visualise the blood-air barrier. We used a standard procedure of described stainings. The thickness of the membrane forming blood-air barrier was measured using a microscope with digital camera Olympus BX41, lens x100 and CellSense software in the PAS stained sections. Optical density of the picture of the trichrome-stained area was outlined and quantified using ImageJ software and its associated colour deconvolution plugin as described previously $(34,35)$.

Immunohistochemical (IHC) and orcein stainings. This immunohistochemical staining was performed with the use of antibodies directed against $\alpha$-Smooth Muscle Actin ( $\alpha$-SMA, Elabscience, polyclonal rabbit anti-human, -mouse and -rat antibody, E-AB-33323, dilution 1:200, previously used by Li et al (36) to assess myofibroblasts that are responsible for collagen fiber production and form blood vessel walls. The exposure of the antigenic sites was performed thermally by incubation in citrate buffer solution with $\mathrm{pH}=6$, in a microwave oven at $800 \mathrm{~W}$, for 3 cycles lasting 5 min each. In order to inhibit endogenous peroxidase activity slides were incubated in $0.3 \%$ perhydrol $\left(\mathrm{H}_{2} \mathrm{O}_{2}\right)$ in methanol for $30 \mathrm{~min}$. The samples were incubated in normal serum for $1 \mathrm{~h}$ to block the non-specific bindings. The material was incubated at $4^{\circ} \mathrm{C}$ overnight $(17 \mathrm{~h})$ in diluted primary antibody. The diaminobenzidine solution (DAB) and hematoxylin colouration were used to visualize the reaction ( $5 \mathrm{~min}$ ). Negative controls were prepared in a similar manner, only the specific primary antibody was omitted. The material was evaluated with a light microscope using lenses x10 and x40. Quantification of the vessel number was determined by the visualization of the $\alpha$-SMA muscle actin in the vessel wall cells. Blood vessels were counted in 

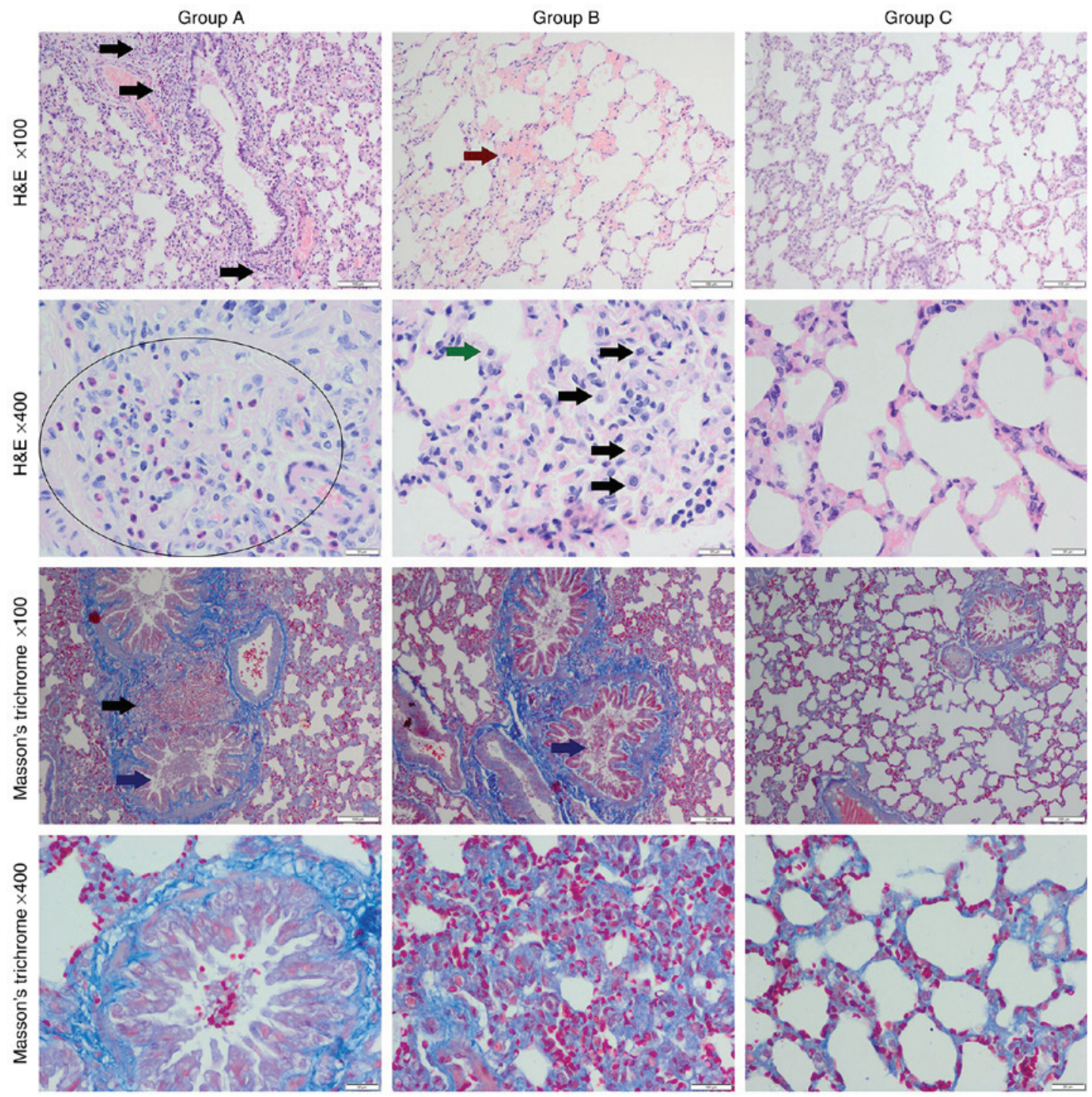

Figure 1. Histological structure of tested lungs. Normal arrangement of the lung tissue with collagen fibers surrounding the bronchioles could be seen in the control group (group C). The e-cig group (group A) exhibited infiltration of eosinophils, erythrocytes and mononuclear cells (black arrows), thickened alveolar septa, and hyperaemia. Collagen depositions within alveolar septa and in peribronchiolar area could also be observed. In the conventional cigarette group (group B), haemorrhage (red arrow), thickened alveolar septa, macrophages (green and black arrows), collagen deposition within thickened alveolar septa, erythrocytes and mucus intrabronchioles could be observed (blue arrow). Magnification, x100 or x400. H\&E, hematoxylin and eosin.

50 fields of view under 100x lens. Elastic fibers were evaluated in orcein staining.

Statistical analysis. The obtained test results were statistically analysed with Statistica 13.0 (StatSoft). The Shapiro-Wilk test was used to assess the data distribution and the Kruskal-Wallis test was used to calculate the P-values. In this regard, a probability (P-value) $<0.05$ was considered statistically significant.

\section{Results}

$H \& E$ staining. A collapse of parenchyma, hyperhagia, hyperplasia of type II of pneumocytes, and an increased number of macrophages was observed in both experimental groups (Fig. 1). Furthermore, in the e-cig group eosinophils and mononuclear cells infiltration was noted, as well as thickened alveolar septa, hyperaemia, intrabronchiolar erythrocytes and the increase of mucus production. In the conventional cigarette group irregularity of alveolar lumen was observed, as well as features of emphysema, vacuolization of cells in the alveolar septa, mucus intrabronchioles and hemorrhage into bronchiole and alveolar lumen.

Masson's Trichrome staining. In the Masson's Trichrome staining, sections of increased collagen deposition within thickened alveolar septa and initial fibrosis was observed in both experimental groups (Fig. 1). The highest optical density score was noted in the conventional cigarette group (Table I). In the control group, normal appearance of the lung tissue and collagen fibres was noted, the latter only surrounded the bronchioles.

PAS and orcein staining. In the PAS staining, an increase of the blood-air barrier-forming membrane thickness was observed in both experimental groups (Table I and Fig. 2). In the orcein staining delicate elastin fibres were noted in 
Table I. Optical Density score of Masson's trichrome staining, thickness of blood-air barrier forming membrane measured in PAS staining and number of blood vessels observed in one field of view at 100X magnification.

\begin{tabular}{|c|c|c|c|c|}
\hline \multirow[b]{2}{*}{ Measured parameter } & \multicolumn{3}{|c|}{ Group } & \multirow[b]{2}{*}{$\mathrm{P}$-value in $\mathrm{U}$ test } \\
\hline & $\mathrm{A}(\mathrm{n}=500)$ & B $(n=500)$ & $C(n=500)$ & \\
\hline $\begin{array}{l}\text { Optical sensity score of Masson's trichrome } \\
\text { staining }\end{array}$ & $0.18 \pm 0.05$ & $0.22 \pm 0.06$ & $0.13 \pm 0.02$ & $\begin{array}{l}\mathrm{A}: \mathrm{C}, \mathrm{P}=0.0002 ; \mathrm{B}: \mathrm{C}, \mathrm{P}<0.0001 \\
\mathrm{~A}: \mathrm{B}, \mathrm{P}=0.0080\end{array}$ \\
\hline $\begin{array}{l}\text { Thickness of blood-air barrier forming } \\
\text { membrane measured in PAS staining, } \mu \mathrm{m}\end{array}$ & $0.40 \pm 0.08$ & $0.44 \pm 0.19$ & $0.20 \pm 0.06$ & $\begin{array}{l}\mathrm{A}: C, P=0.0300 ; \mathrm{B}: \mathrm{C}, \mathrm{P}=0.0200 \\
\mathrm{~A}: \mathrm{B}, \mathrm{P}=0.4000\end{array}$ \\
\hline $\begin{array}{l}\text { Number of blood vessels observed in one } \\
\text { field of view at x } 100 \text { magnification }\end{array}$ & $6.17 \pm 2.04$ & $7.86 \pm 2.6$ & $3.38 \pm 1.36$ & $\begin{array}{l}\mathrm{A}: \mathrm{C}, \mathrm{P}=0.0009 ; \mathrm{B}: \mathrm{C}, \mathrm{P}<0.0001 \\
\mathrm{~A}: \mathrm{B}, \mathrm{P}=0.1200\end{array}$ \\
\hline
\end{tabular}

Mann-Whitney's U test. $\mathrm{P}<0.05$ was considered to indicate a statistically significant difference. Statistica 13.0 software StatSoft was used. Group A, animals exposed to scent free e-cig vapour. Group B, rats exposed to the smoke from 10 traditional cigarettes. Group C, control group.
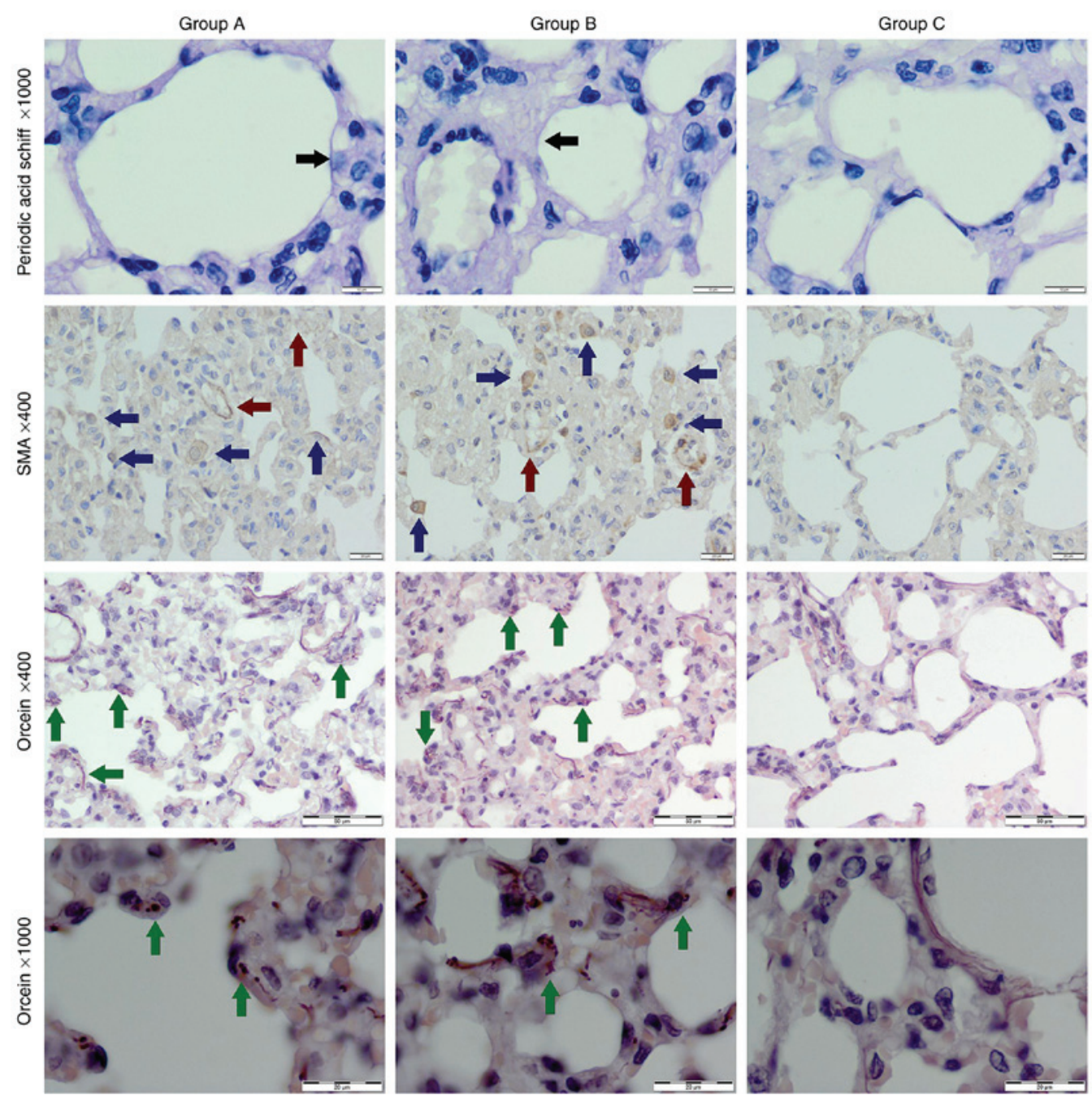

Figure 2. Control group (group C) exhibited normal alveoli, single myofibroblast and blood vessels with positive expression of $\alpha$-SMA, and delicate normal elastic fibers within alveolar septa in orcein staining (green arrow). In the e-cig group (group A) and the conventional cigarette group (group B), thickened basement membrane (black arrows), vacuolization of cells in alveolar septa, more numerous $\alpha$-SMA positive myofibroblasts (blue arrows) and blood vessels (red arrows), and thicker, disrupted, sparse elastic fibers (green arrows) were observed. Original magnification, x400 or x1,000. SMA, smooth muscle actin.

the control group. An initial elastolysis was observed in both experimental groups-4 elastic fibres were disrupted, sparse, irregular and thickened (Fig. 2).
Immunohistochemical staining, $\alpha$-SMA. The highest expression of $\alpha$-SMA was seen in the conventional cigarette group B (Fig. 2). The most numerous myofibroblasts were 
within parenchyma of that same group $(20 \pm 5$ in one field of view), fewer in e-cig group A (17 \pm 6 in one field of view) and just single ones in the control group. Numbers of $\alpha$-SMA positive blood vessels were the highest in the conventional cigarette group (Table I).

\section{Discussion}

Never-smokers including adolescents and young adults reach out for e-cigarettes more and more frequently. Their knowledge concerning these products is at best insufficient $(18,37-39)$. What is more, the use of e-cigs may also lead to nicotine dependence and have harmful impact on health $(22,40,41)$. The exposition to vapours produced by e-cig has caused morphological alterations in the human lung fibroblasts, induced the oxidative stress and inflammatory response in the lungs of mice $(7,14,21)$. A case of acute alveolitis with intra-alveolar fibrosis, infiltration of macrophages, eosinophils and neutrophils has been described by Itoh et al (42). The vapour generated by e-cig probably affects the gene expression of the circadian rhythm-related proteins in healthy and sick people (43). Among others, the exposure to e-cig may cause the induction of genes involved in oxidative and xenobiotic stress pathways, increased reactive oxygen species production, decreased expression of genes involved in cilia assembly and movement in the human bronchial epithelial cells (44).

In the current study we used rat that is a representative model for human exposure to e-cigarette vapour and conventional cigarette smoke. The current study utilised similar methodology as that proposed by Canistro et al (27) in terms of animal exposure to e-cigarette vapour.

To the best of the authors' knowledge, the present study is the first to demonstrate that the exposition to vapour or smoke disrupts the structure of the lung tissue. Numerous pathological changes such as the bronchial haemorrhage and the increase of alveolar septa thickness, infiltration of eosinophils and macrophages were observed in the lungs of rats exposed to vapour. Yet, more significant destructive changes within the features of the emphysema and fibrosis were present in the lungs of animals exposed to conventional smoke. The elastic fibres responsible for the regulation of alveolar thickness as well as the thickness of bronchiole lumen, were disrupted in both experimental groups.

Our results are in line with the study of Valença et al (45), in which rats receiving nicotine intraperitoneally had disorganised parenchyma and inflammatory cells infiltration. Moreover, elastic fibres were disrupted, the thickness of alveolar septa and the number of parenchyma vessels was increased (45). The alveolar septa thickening may depend on the increased volume of blood capillaries, inflammatory infiltration and oedema. Moreover, cigarette smoking has activated the neutrophil and macrophage elastases which damage the elastic fibres and lead to emphysema (45).

It is presumed that the observed disruptive changes of the lung tissues are probably associated with oxidative stress and the dysfunction of blood-air barrier caused by the toxic substances present in smoke or vapour $(3,46)$. The study conducted by Schweitzer et al (46) has shown that nicotine contained in e-cig liquid triggered the disruption of endothelial barrier in the cultured cell monolayers and increased lung inflammation by the induction of oxidative stress in mice. Other study proved that nicotine applied subcutaneously in a daily dose of $1.5 \mathrm{mg} / \mathrm{kg}$ for 4 weeks may damage rat lung tissue and may lead to the intraparenchymal haemorrhage, respiratory epithelial proliferation, extensive interstitial fibrosis and empchysematous changes (3). Reinikovaite et al (47) showed that vapour of e-cig can damage lung tissue comparably to conventional cigarette smoke. On the contrary to our study, the emphysematous changes and the decrease of lung capillaries number was observed in rats exposed to either smoke or vapour similarly to the rats exposed to nicotine administered subcutaneously (47).

The acute disruption and inflammation as well as ineffectiveness of regeneration mechanisms caused a chronic condition leading to the alterations of lung architecture and pulmonary fibrosis. The nicotine stimulates fibroblast proliferation and collagen type I production (5). Additionally, nicotine may cause the induction of the fibroblasts differentiation into myofibroblasts. The latter are responsible for the pro-fibrotic extracellular matrix proteins secretion. Consequently, the accumulation of collagen within lung tissue leads to fibrosis and decreases the gas exchange area $(22,48)$.

In the current study, the expression of $\alpha$-SMA, a marker for myofibroblasts, was overexpressed in both experimental groups, but to a higher extent in the conventional cigarette group. In conclusion, the current study proves that usage of e-cigarettes leads to milder pathological changes when compared to the smoking of conventional cigarettes. However, e-cigs cannot be considered to be completely safe $(38,49)$. Apparently, the exposure to nicotine in the form of e-cig leads to the degeneration of the lung tissue, formation of collagen deposits, the activation of eosinophils, myofibroblasts and angiogenesis. Furthermore, those changes may lead to the alterations of lung architecture which additionally hinders the gas exchange in areas.

The current study was conducted with the use of laboratory animals for a limited period of six weeks. Only male rats were used to retain homogeneity of studied groups-further studies should include the intersex comparison.

\section{Acknowledgements}

Not applicable.

\section{Funding}

The present study was supported by a grant of the Minister of Science and Higher Education (grant no. MNmb 246).

\section{Availability of data and materials}

All data generated or analysed during this study are included in this published article.

\section{Authors' contributions}

EWG and PCW conceived and designed the study. EWG and MKZ conducted experiments. EWG, MKZ and BJJ performed histological analysis. BJJ and PCW contributed reagents. EWG 
and $\mathrm{KC}$ analyzed data. EWG, MKZ and $\mathrm{KC}$ wrote the manuscript. All authors read and approved the final manuscript.

\section{Ethics approval and consent to participate}

The experiment was conducted with the formal approval of the Local Ethics Committee for Animal Experiments of the University of Life Sciences in Lublin (approval no. 30/2015).

\section{Patient consent for publication}

Not applicable.

\section{Competing interests}

The authors declare that they have no competing interests.

\section{References}

1. Mishra A, Chaturvedi P, Datta S, Sinukumar S, Joshi P and Garg A: Harmful effects of nicotine. Indian J Med Paediatr Oncol 36: 24-31, 2015.

2. Ratajczak A, Feleszko W, Smith DM and Goniewicz M: How close are we to definitively identifying the respiratory health effects of e-cigarettes? Expert Rev Respir Med 12: 549-556, 2018.

3. Al-Obaidi S, Mathew TC and Dean E: Exercise may offset nicotine-induced injury in lung tissue: A preliminary histological study based on a rat model. Exp Lung Res 38: 211-221, 2012.

4. Avino P, Scungio M, Stabile L, Cortellessa G, Buonanno G and Manigrasso M: Second-hand aerosol from tobacco and electronic cigarettes: Evaluation of the smoker emission rates and doses and lung cancer risk of passive smokers and vapers. Sci Total Environ 642: 137-147, 2018.

5. Vicary GW, Ritzenthaler JD, Panchabhai TS, Torres-González E and Roman J: Nicotine stimulates collagen type I expression in lung via $\alpha 7$ nicotinic acetylcholine receptors. Respir Res 18: 115, 2017.

6. Benowitz NL, Hukkanen J and Jacob P III: Nicotine chemistry, metabolism, kinetics and biomarkers. Handb Exp Pharmacol 192 29-60, 2009.

7. Lerner CA, Sundar IK, Yao H, Gerloff J, Ossip DJ, McIntosh S, Robinson R and Rahman I: Vapours produced by electronic cigarettes and e-juices with flavourings induce toxicity, oxidative stress, and inflammatory response in lung epithelial cells and in mouse lung. PLoS One 10: e0116732, 2015.

8. Wu Q, Jiang D, Minor M and Chu HW: Electronic cigarette liquid increases inflammation and virus infection in primary human airway epithelial cells. PLoS One 9: e108342, 2014.

9. Yong HH, Hitchman SC, Cummings KM, Borland R, Gravely SM, McNeill A and Fong GT: Does the regulatory environment for E-cigarettes influence the effectiveness of E-cigarettes for smoking cessation?: Longitudinal findings from the ITC four country survey. Nicotine Tob Res 19: 1268-1276, 2017.

10. Mohamed MH, Rahman A, Jamshed S and Mahmood S: Effectiveness and safety of electronic cigarettes among sole and dual user vapers in Kuantan and Pekan, Malaysia: A six-month observational study. BMC Public Health 18: 1028, 2018.

11. McRobbie H, Bullen C, Hartmann-Boyce J and Hajek P: Electronic cigarettes for smoking cessation and reduction. Cochrane Database Syst Rev: Dec 17, 2014 (Epub ahead of print). doi: 10.1002/14651858.CD010216.pub2.

12. Hartmann-Boyce J, Chepkin SC, Ye W, Bullen C and Lancaster T: Nicotine replacement therapy versus control for smoking cessation. Cochrane Database Syst Rev 5: CD000146, 2018.

13. Wagener TL, Floyd EL, Stepanov I, Driskill LM, Frank SG, Meier E, Leavens EL, Tackett AP, Molina N and Queimado L: Have combustible cigarettes met their match? The nicotine delivery profiles and harmful constituent exposures of second-generation and third-generation electronic cigarette users. Tob Control 26: e23-e28, 2017.

14. Verhaegen A and Van Gaal L: Do E-cigarettes induce weight changes and increase cardiometabolic risk? A signal for the future. Obes Rev 18: 1136-1146, 2017.
15. Camenga DR, Kong G, Cavallo DA and Krishnan-Sarin S: Current and former Smokers' use of electronic cigarettes for quitting smoking: An exploratory study of adolescents and young adults. Nicotine Tob Res 19: 1531-1535, 2017.

16. Buu A, Hu YH, Piper ME and Lin HC: The association between e-cigarette use characteristics and combustible cigarette consumption and dependence symptoms: Results from a national longitudinal study. Addict Behav 84: 69-74, 2018.

17. Sassano MF, Davis ES, Keating JE, Zorn BT, Kochar TK, Wolfgang MC, Glish GL and Tarran R: Evaluation of e-liquid toxicity using an open-source high-throughput screening assay. PLoS Biol 16: e2003904, 2018.

18. Richmond SA, Pike I, Maguire JL and Macpherson A: E-cigarettes: A new hazard for children and adolescents. Paediatr Child Health 23: 255-259, 2018.

19. Greenhill R, Dawkins L, Notley C, Finn MD and Turner JJD: Adolescent awareness and use of electronic cigarettes: A review of emerging trends and findings. J Adolesc Health 59: 612-619, 2016.

20. McMillen R, Tanski S, Wilson K, Klein JD and Winickoff JP: Adolescent use of different E-cigarette products. Pediatrics 142: pii: e20180260, 2018.

21. Glynos C, Bibli SI, Katsaounou P, Pavlidou A, Magkou C, Karavana V, Topouzis S, Kalomenidis I, Zakynthinos S and Papapetropoulos A: Comparison of the effects of e-cigarette vapor with cigarette smoke on lung function and inflammation in mice. Am J Physiol Lung Cell Mol Physiol 315: L662-L672, 2018.

22. Javed F, Kellesarian SV, Sundar IK, Romanos GE and Rahman I: Recent updates on electronic cigarette aerosol and inhaled nicotine effects on periodontal and pulmonary tissues. Oral Dis 23 . 1052-1057, 2017.

23. Khan MS, Khateeb F, Akhtar J, Khan Z, Lal A, Kholodovych V and Hammersley J: Organizing pneumonia related to electronic cigarette use: A case report and review of literature. Clin Respir J 12: 1295-1299, 2018

24. Walele T, Bush J, Koch A, Savioz R, Martin C and O'Connell G: Evaluation of the safety profile of an electronic vapour product used for two years by smokers in a real-life setting. Regul Toxicol Pharmacol 92: 226-238, 2018.

25. Gaur S and Agnihotri R: Health effects of trace metals in electronic cigarette Aerosols-A systematic review. Biol Trace Elem Res 188: 295-315, 2019.

26. Williams M, Villarreal A, Bozhilov K, Lin S and Talbot P: Metal and silicate particles including nanoparticles are present in electronic cigarette cartomizer fluid and aerosol. PLoS One 8: e57987, 2013

27. Canistro D, Vivarelli F, Cirillo S, Babot Marquillas CB, Buschini A, Lazzaretti M, Marchi L, Cardenia V, RodriguezEstrada MT, Lodovici M, et al: E-cigarettes induce toxicological effects that can raise the cancer risk. Sci Rep 7: 2028, 2017.

28. Burkholder TH, Niel L, Weed JL, Brinster LR, Bacher JD and Foltz CJ: Comparison of carbon dioxide and argon euthanasia: Effects on Behavior, Heart Rate, and respiratory lesions in rats. J Am Assoc Lab Anim Sci 49: 448-453, 2010.

29. Fawell JK, Thomson C and Cooke L: Respiratory artefact produced by carbon dioxide and pentobarbitone sodium euthanasia in rats. Lab Anim 6: 321-326, 1972.

30. Novotný L, Misík J, Karasová J, Kuča K and Bajgar J: Influence of different ways of euthanasia on the activity of cholinesterases in the rat. J App Biomedicine 7: 133-136, 2009.

31. Pierozan P, Jernerén F, Ransome Y and Karlsson O: The choice of euthanasia method affects metabolic serum biomarkers. Basic Clin Pharmacol Toxicol 121: 113-118, 2017.

32. Stutler SA, Johnson EW, Still KR, Schaeffer DJ, Hess RA and Arfsten DP: Effect of method of euthanasia on sperm motility of mature Sprague-Dawley rats. J Am Assoc Lab Anim Sci 46: 13-20, 2007.

33. Brooks DM and Hand WR Jr: A Cost analysis: General endotracheal versus regional versus monitored anesthesia care. Mil Med 164: 303-305, 1999.

34. Varghese F, Bukhari AB, Malhotra R and De A: IHC profiler: An open source plugin for the quantitative evaluation and automated scoring of immunohistochemistry images of human tissue samples. PLoS One 9: e96801, 2014

35. Hernández-Morera P, Castaño-González I, TraviesoGonzález CM, Mompeó-Corredera B and Ortega-Santana F: Quantification and statistical analysis methods for vessel wall components from stained images with Masson's Trichrome. PLoS One 11: e0146954, 2016. 
36. Li Z, Liu X, Wang B, Nie Y, Wen J, Wang Q and Gu C: Pirfenidone suppresses MAPK signalling pathway to reverse epithelial-mesenchymal transition and renal fibrosis. Nephrology (Carlton) 22: 589-597, 2017.

37. Jongenelis MI, Brennan E, Slevin T, Kameron C, Rudaizky D and Pettigrew S: Differences in use of electronic nicotine delivery systems by smoking status and demographic characteristics among Australian young adults. Health Promot J Austr 30: 207-211, 2019

38. Rohde JA, Noar SM, Horvitz C, Lazard AJ, Cornacchione Ross J and Sutfin EL: The role of knowledge and risk beliefs in adolescent E-Cigarette use: A pilot study. Int J Environ Res Public Health 15: pii: E830, 2018.

39. Melin K, Conte-Schmidt N, Martínez-Arroyo K, Rosa-Pérez K, Soto-Avilés AE and Hernández-Muñoz JJ: Knowledge and perceptions of E-cigarettes and the motivations for their use: Talking to smokers (E-cigarettes and/or Conventional Cigarettes) and Non-smokers in Puerto Rico. P R Health Sci J 37: 148-154, 2018.

40. Hughes JR and Callas PW: Prevalence of withdrawal symptoms from electronic cigarette cessation: A cross-sectional analysis of the US Population Assessment of Tobacco and Health. Addict Behav 91: 234-237, 2019.

41. Case KR, Mantey DS, Creamer MR, Harrell MB, Kelder SH and Perry CL: E-cigarette-specific symptoms of nicotine dependence among Texas adolescents. Addict Behav 84: 57-61, 2018.

42. Itoh M, Aoshiba K, Herai Y, Nakamura H and Takemura T: Lung injury associated with electronic cigarettes inhalation diagnosed by transbronchial lung biopsy. Respirol Case Rep 6: e00282, 2017.

43. Lechasseur A, Jubinville É, Routhier J, Bérubé JC, Hamel-Auger M, Talbot M, Lamothe J, Aubin S, Paré MÈ, Beaulieu MJ, et al: Exposure to electronic cigarette vapors affects pulmonary and systemic expression of circadian molecular clock genes. Physiol Rep 5: e13440, 2017.
44. Moses E, Wang T, Corbett S, Jackson GR, Drizik E, Perdomo C, Perdomo C, Kleerup E, Brooks D, O'Connor G, et al: Molecular Impact of electronic cigarette aerosol exposure in human bronchial epithelium. Toxicol Sci 155: 248-257, 2017.

45. Valença SS, de Souza da Fonseca A, da Hora K, Santos R and Porto LC: Lung morphometry and MMP-12 expression in rats treated with intraperitoneal nicotine. Exp Toxicol Pathol 55: 393-400, 2004

46. Schweitzer KS, Chen SX, Law S, Van Demark M, Poirier C, Justice MJ, Hubbard WC, Kim ES, Lai X, Wang M, et al: Endothelial disruptive proinflammatory effects of nicotine and e-cigarette vapor exposures. Am J Physiol Lung Cell Mol Physiol 309: L175-L187, 2015.

47. Reinikovaite V, Rodriguez IE, Karoor V, Rau A, Trinh BB, Deleyiannis FW and Taraseviciene-Stewart L: The effects of electronic cigarette vapour on the lung: Direct comparison to tobacco smoke. Eur Respir J 51: 1701661, 2018.

48. Blaauboer ME, Boeijen FR, Emson CL, Turner SM, Zandieh-Doulabi B, Hanemaaijer R, Smit TH, Stoop R and Everts V: Extracellular matrix proteins: A positive feedback loop in lung fibrosis? Matrix Biol 34: 170-178, 2014.

49. Carson JL, Zhou L, Brighton L, Mills KH, Zhou H, Jaspers I and Hazucha M: Temporal structure/function variation in cultured differentiated human nasal epithelium associated with acute single exposure to tobacco smoke or E-cigarette vapor. Inhal Toxicol 29: 137-144, 2017.

(i) $\Theta$ This work is licensed under a Creative Commons Attribution-NonCommercial-NoDerivatives 4.0 International (CC BY-NC-ND 4.0) License. 